\title{
In Situ Synthesis of a Wear Resistant Layer on the Surface of Low Carbon Steel produced by Laser Melt Injection Technology
}

\author{
Valéria Mertinger ${ }^{1, a}$, Gábor Buza ${ }^{2, b}$, Balázs Major ${ }^{3, c}$ \\ ${ }^{1}$ Institute of Materials Sciences, University of Miskolc, 3515 Miskolc-Egyetemváros, Hungary \\ ${ }^{2}$ Institute of Materials Sciences and Technology, Bay Zoltán Nonprofit Ltd., Budapest, Hungary \\ ${ }^{3}$ Institute of Enzymology, Research Centre for Natural Sciences, Hungarian Academy of Sciences, \\ 29 Karolina str. Budapest, Hungary, $\mathrm{H}-1113$
}

afemvali@uni-miskolc.hu (corresponding author), bbuza@bzaka.hu, ${ }^{\mathrm{c}} \mathrm{csybe} @ e n z i m . h u$

Keywords: titanium carbide, in-situ synthesis, laser treatment

\begin{abstract}
Titanium and his compounds are one of the most frequently used reinforcing particles in iron - ceramic composite materials. These materials will possess special characteristics because they are quenchable, their hardness can be increased by heat treatment and they can be quite easily machined. The point of the technology developed in the Bay Zoltán Institute of Materials Sciences and Technology is to form the reinforcing layer on the surface of the sample in an in situ way by melting the surface of the low carbon steel and the laminar carbon felt using laser beam while the titanium metal powder is simultaneously added to the melt. Several methods (metallographic examinations, selective area hardness measurements, SEM, and XRD) were applied to answer the questions about the optimal conditions for the in situ synthesis of a wear resistant layer.
\end{abstract}

\section{Introduction}

For certain applications it is sufficient to improve only the surface layer of the material; so many of the surface hardening process are used for this purpose [1]. Laser Melt Injection (LMI) technology is one of the most frequently used method to improve surface characteristics (hardness, wear and oxidation resistance) of metallic alloys [2], not only titanium [3,4,5] and steels [6,7], but also lights materials such as aluminum [8] and magnesium. During Laser Melt Injection particles are inserted by an inert gas flow into the substrate surface melted by a fast moving laser beam. The particles are usually very hard such as carbides, nitrides and oxides and their size range is very wide from $200 \mu \mathrm{m}$ to the nano scale. The hard particles bonded by a metal matrix is known to be a perfect metal matrix composite. Moreover in-situ reinforced composites generally show better advantages than ones with external additives since those are thermodynamically stable and the reinforcementmatrix interfaces are clean and many problems such as wetting characteristic or density differences are eliminated. The in-situ formed reinforcing particles are also finer in size and their distribution in the matrix is more uniform $[9,10]$. Using laser beam leads to low heat input to the partially melted substrate material resulting a strong metallurgical bond composite surface layer compared to the other surface hardening process. The continuous wave laser has been applied greatly in this field, but there are few studies about using pulse wave [11, 12], which brings a high cooling rate and low heat input. The most important parameters of this surface hardening process are the size control and the quality of the distribution of the synthesized particles.

The objective of this work was to explore the synthesis of the Fe-TiC reinforced coating on cheap low alloy carbon steel with the pre-placed graphite layer using a $\mathrm{CO}_{2}$ continuous wave laser. The insitu production of bulk Fe-TiC composites has been known for two decades. The in-situ formation of the same composite by LMI has been reported only in very limited cases [13]. It was probably due to the expectation that the process time is too short for the necessary processes such as carbon and titan dissolution into the melt iron matrix and the formation and precipitation the particles.

During our examinations the aim was to understand the complex metallurgical processes. Namely, answers for the following questions were searched: 
What phases form?

$\odot$ Does titanium carbide form during the laser treatment, and if so, under what conditions?

$(\rightarrow$ What is the optimal amount of the titanium added to the melt?

(๖) What is the distribution of the titanium in its compounds with the majority of iron and carbon in the melt during to the high rate heating and cooling (micro and macro segregation?

(.) What is the hardness distribution of the reinforced structure?

The methods applied to answer these questions were metallographic examinations by means of optical microscope, selective area hardness measurements, scanning electron microscope examinations, composition analysis, phase identification and solute content determination by means of selective area x-ray diffraction in the Institute of Material Sciences at the University of Miskolc.

\section{Experimental setup}

The substrate sample consisted of a 5 pieces carbon steel sheets with $3 \mathrm{~mm}$ in thickness (Grade: S355MC. Number: 1.0976. Standard: EN 10149 - 2) and soft carbon felts (Sigratherm ${ }^{\circledR}$ GFD 2 ) between the steel layers were inserted as a carbon source. A $5 \mathrm{~kW} \mathrm{CO} \mathrm{CO}_{2}$ continuous wave laser (Trumph TLC 105) was used to melt the surface of the substrate with a laser power of 2,5 kW. The laser spot with a diameter of $2 \mathrm{~mm}$ was moving along the substrate, in parallel direction with the normal of the sheets layers with a velocity of $500 \mathrm{~mm} / \mathrm{min}$. Eight laser tracks were drawn parallel to each other with $1 \mathrm{~mm}$ offset. Each laser track was $25 \mathrm{~mm}$ long. The thickness of the remelted layer was about 1-1,5 $\mathrm{mm}$. The laser system was equipped and moved together with a powder feeding system. Pure titanium powder with the $\sim 70 \mu \mathrm{m}$ grain size was blown into the melted substrate under the angle of $45^{\circ}$ using argon as carrier gas. The flow rate of the carrier gas was $2 \mathrm{l} / \mathrm{min}$. Argon was also used as a protecting gas during the treatment with $81 / \mathrm{min}$ flow rate. Four experiments were performed with different inserted titan volumes with increasing sequence numbers 4, 6, 8, 10 . Parallel experiments were also done (sample mark 'a' and 'b'). Fig.1. shows the sample setup and the labeling of the $4 \mathrm{~b}$ sample while Fig.2. shows the SEM image of the steel and the carbon felt parts of the substrate.

After the LMI treatment the samples were prepared (grinding, polishing, etching with nital etchant), for metallographic examination. Zeiss AxioVision Imager $\mathrm{m} 1 \mathrm{M}$ with motorized stage, scanning electron microscopy (1830I Amray SEM with EDAX system), Bruker D8 advance XRD system with $\operatorname{CoK} \alpha$ radiation and MonoCap optic were used. Selective area hardness was measured by Wilson Instrument TUKON 2100B equipment with load of $3000 \mathrm{~g}$, inserting time $15 \mathrm{~s}$ and with $400 \mu \mathrm{m}$ offset.

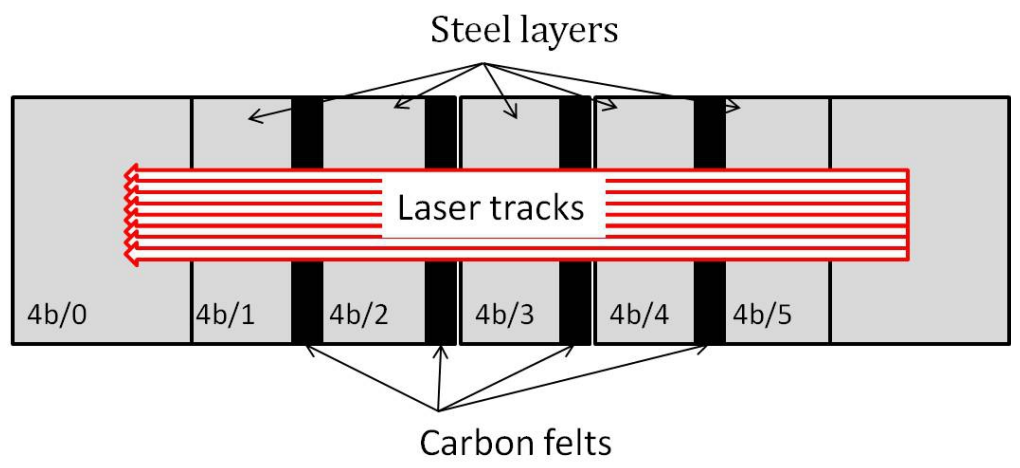

Figure 1. Sample setup and labeling 


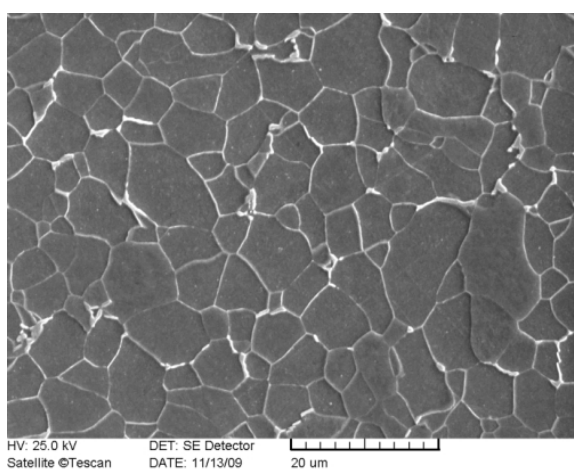

a)

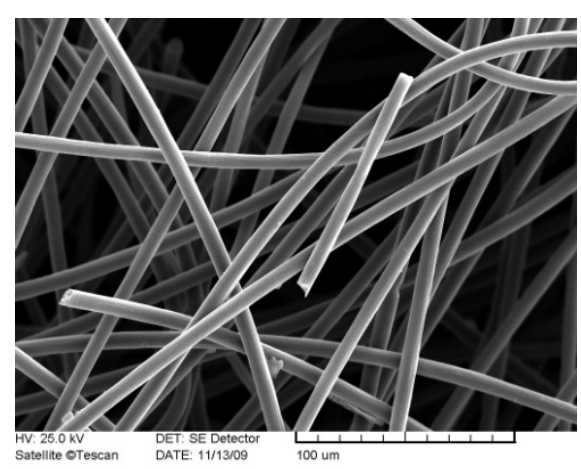

b)

Figure 2. SEM image of the substrate materials a) steel S355MC, b) soft carbon felts (Sigratherm ${ }^{\circledR}$ GFD2)

After the LMI treatment the sample marked ' $b$ ' was taken apart and the initial steel sheets were investigated. The normal of the metallographic surface was parallel with the direction of laser tracks. The sample marked 'a' was tested in the compact way. The normal of the metallographic surface was perpendicular or has an acute angle with the direction of the laser track.

\section{Experimental result and discussion}

If we compare the macrostructure of the reinforced layers it is evident that when the inserted $\mathrm{Ti}$ volume is too high the layer becomes very brittle, discontinuous and the bond between the substrate and the reinforced zone is very pure. The $10 \mathrm{~b} / 4$ and the $8 \mathrm{~b} / 3$ samples represent examples for this situation in the Fig 3.

Contrarily in the case of lower inserted Ti volume (sample 6b/2, 4b/2) very good macroscopic structure were observed. In the microscopic scale a well defined banded structure is shown in Fig. 3 and 4 . The contrast of the first track is always different from the others, which results in a different hardness value too. The last track is homogeneous but the 2-7 tracks show alternating light and dark bands with low and high hardness respectively (Fig. 5).
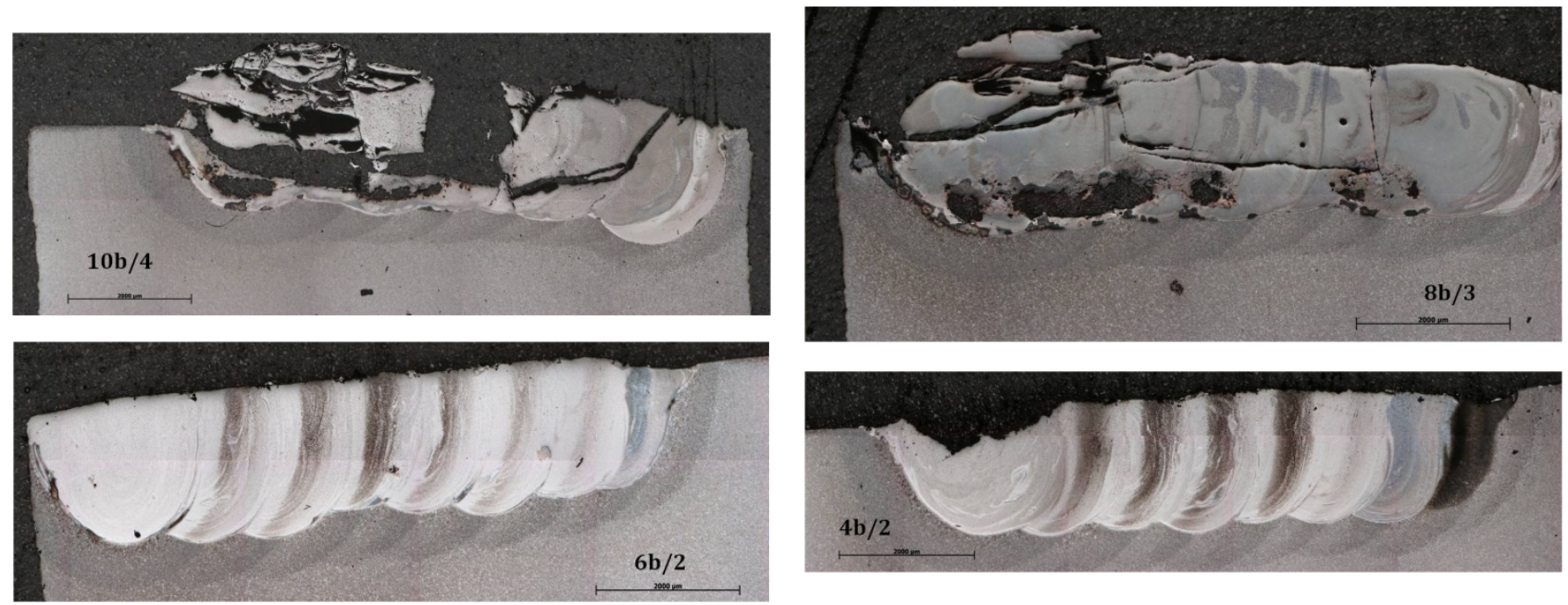

Figure 3. Mosaic LM image of sample with different Ti contents. (Increasing sequence numbers 4, $6,8,10)$, the length of the scale bars are $2 \mathrm{~mm}$ 

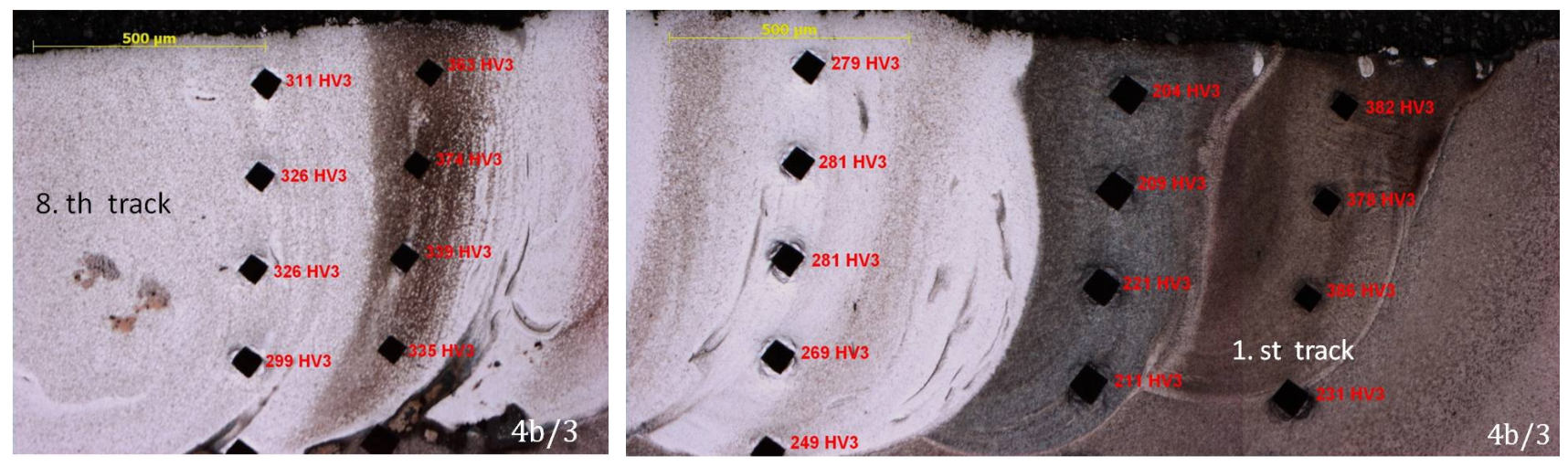

Figure 4. LM images of sample number $4 \mathrm{~b} / 3$ with the hardness results
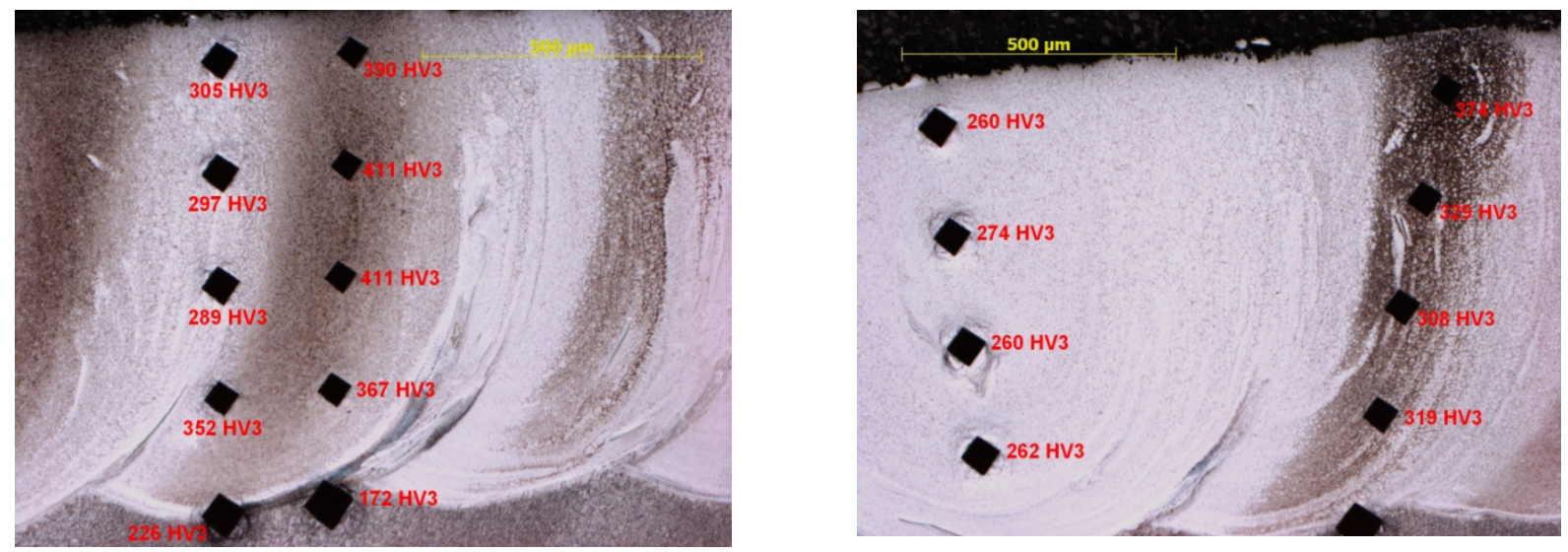

Figure 5. LM images of sample number $4 b / 4$ with the hardness results

The microstructures and the result of EDAX analysis related to the different hardness and LM contrast are shown In Fig.6. Three different structures can be distinguished in both pictures: a homogeneous solid-solution type with number 3, a dark fine globular or equaxial dendrite with high Ti content with number 2 , and a two phases structure most likely eutectic or eutectoid with number 1. The two phases structure (area No. 1) is much more frequent in the dark band of the sample.

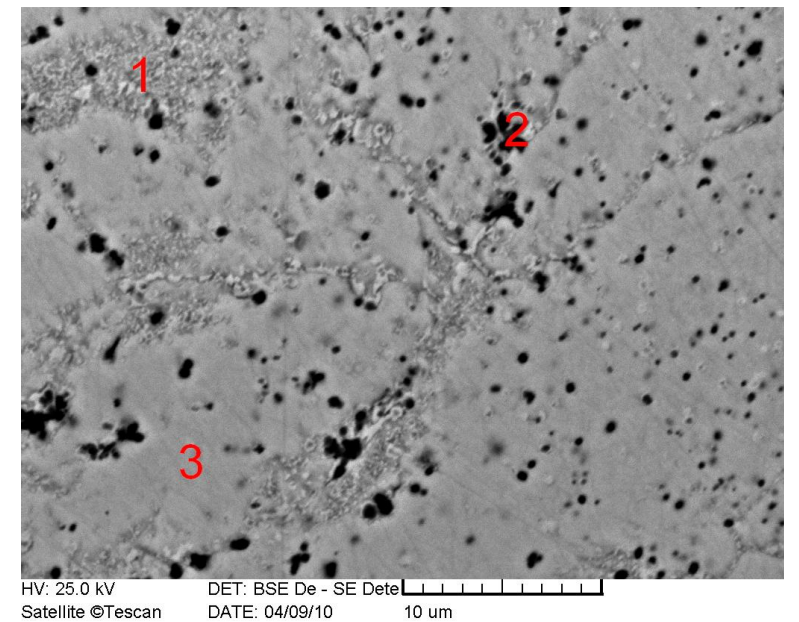

a)

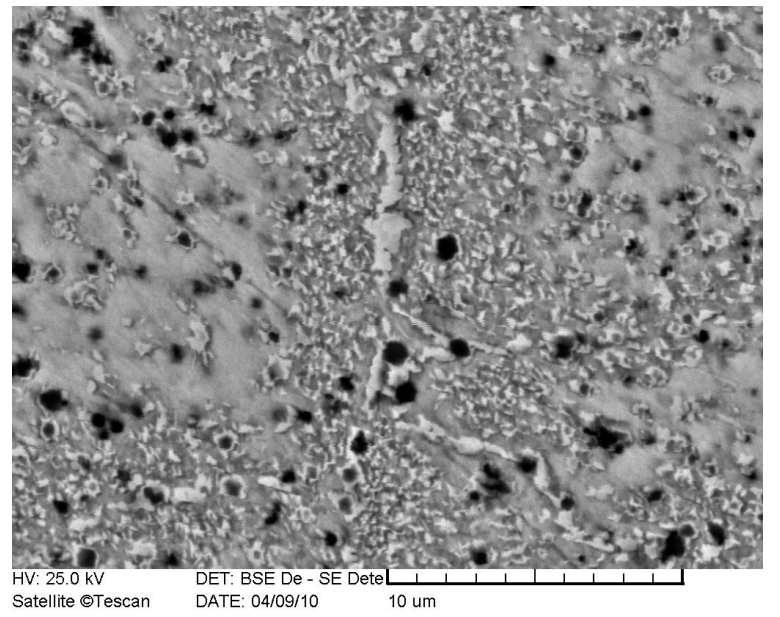

b)

Figure 6.SEM structures correspond to the light (a) and dark (b) LM bands in the sample No. $4 \mathrm{~b} / 3$. EDAX wt\%: area No.1: $8 \mathrm{Ti}, 1 \mathrm{Mn}, 91 \mathrm{Fe}$, area No.2:21Ti, 1Mn, 79Fe, area No3: $6 \mathrm{Ti}, 1 \mathrm{Mn}, 93 \mathrm{Fe}$

The XRD spectrum of sample 10a is shown in Fig.7. Three phases can be identified: the ferrite solid solution, the $\mathrm{Fe}_{2} \mathrm{Ti}$ intermetallic and a small amount of TiC. The selective area diffraction presented the same result in the different parts of the samples, only the volume fractions were 
differed. The ferrite phase has a well defined theta shift which is resulted from the different amount of the Ti content. In different areas of the reinforced layer $6,4 \%, 6,8 \%$ and $9 \%$ Ti solution were measured.

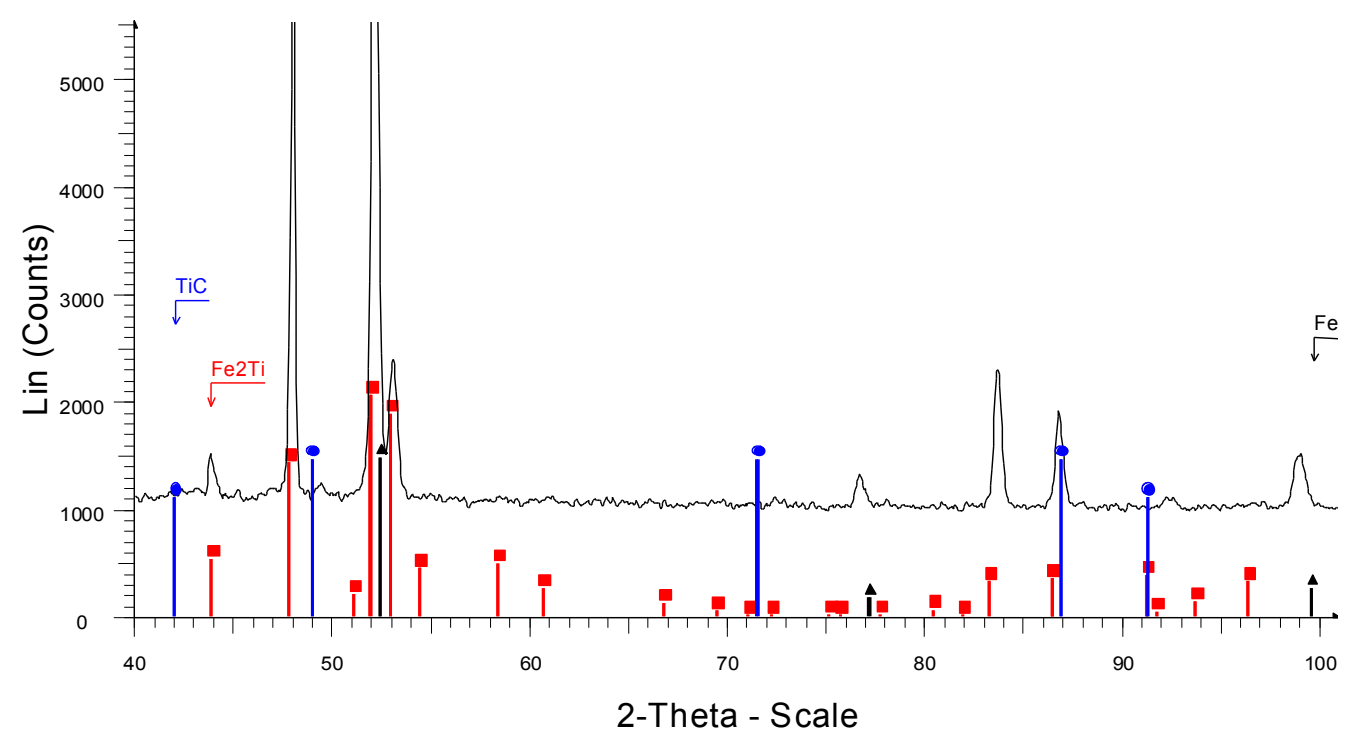

Figure 7. XRD spectrum about the 10a sample

\section{Summary}

LMI technology was successfully used to improve the surface quality of low carbon steel by $\mathrm{Ti}$ powder and $\mathrm{C}$ felt injection. The optimum value of the Ti powder injection was determined to form a compact reinforcement layer. The layer has a banded structure with altering different hardnesses and structures. Ferrite solid solution with different $\mathrm{Ti}$ concentrations $(6,4-9 \%), \mathrm{Fe}_{2} \mathrm{Ti}$ intermetallic phase and a small amount of $\mathrm{TiC}$ were determined in the reinforced part of the substrate. The microstructure investigation demonstrated that the rise in hardness is induced by the high volume of ferrite+Fe $\mathrm{Fe}_{2} \mathrm{Ti}$ eutectoid phases.

\section{Acknowledgements}

The described work was carried out as part of the TÁMOP-4.2.1.B-10/2/KONV-2010-0001 project in the framework of the New Hungarian Development Plan. The realization of this project is supported by the European Union, co-financed by the European Social Fund.

\section{References}

[1] L.A. Dobrzánski, K. Labisz, E. Jonda, A. Klimpel, Comparison of the surface alloying ofthe 32CrMoV12-28 tool steel usingTiC and WC powder, Journal of Materials Processing Technology 191 (2007) 321-325

[2] Yanbin Chen, Dejian Liu,Fuquan Li, Liqun Li, WCp/Ti-6Al-4V graded metal matrix composites layer produced by laser melt injection, Surface \& Coatings Technology 202 (2008) 4780-4787

[3] Mitun Das, Vamsi Krishna Balla, Debabrata Basu, Susmita Bose and Amit Bandyopadhyay, Laser processing of SiC-particle-reinforced coating on titanium, Scripta Materialia 63 (2010) 438441 
[4] Mitun Das, Sandip Bysakh, Debabrata Basu at all, Microstructure, mechanical and wear properties of laser processed $\mathrm{SiC}$ particle reinforced coatings on titanium, Surface \& Coatings Technology 205 (2011) 4366-4373

[5] B.S. Yilbasa, S. Akhtara, B.J. Abdul Aleema, C. Karatasb, Laser gas-assisted processing of carbon coated and TiC embedded Ti-6Al-4V alloy surface, Applied Surface Science 257 (2010) $531-537$

[6] O. Verezub, Z. Kálazi, G Buza, N. V. Verezub, G. Kaptay. In-situ synthesis of a carbide reinforced steel matrix surface nanocomposite by laser melt injection technology and subsequent heat treatment, Surface and Coatings Technology (2009) 203, 3049-3057

[7] F. Akhtara, S.J. Guoa, Microstructure, mechanical and fretting wear properties of TiC stainless steel composites, Materials Characterization 59 (2008), 84-90

[8] Sveda M; Roosz A; Buza G, Formation of lead bearing surface layers on aluminum alloys by laser alloying, Materials Science Forum Volume: 508 (99-104), 2006

[9] L. Fouilland-Paille, S. Ettaqi, S. Benayoun, J.J. Hantzpergue, Structural and mechanical characterization of $\mathrm{Ti} / \mathrm{TiC}$ cermet coatings, synthesized by laser melting, Surface and Coatings Technology 88 (1996) 204-211

[10] P. Schaaf, M. Kahle, E. Carpene, Reactive laser synthesis of carbides and nitrides, Applied Surface Science 247 (2005) 607-615

[11] M.J. Hamedi, M.J.Torkamany,J.Sabbaghzadeh, Effect of pulsed laser parameters on in-situ TiC synthesis in laser surface treatment, Optics and Lasers in Engineering 49 (2011) 557-563

[12] G. Radhakrishnan, P.M. Adams, Pulsed-laser deposition of particulate-free TiC coatings for tribological applications, Appl. Phys. A 69 [Suppl.], S33-S38 (1999)

[13] Tamer Ezz, Philip Crouse, Lin Li, Zhu Liu, Synthesis and coating of micro-metal-matrix composite by combined laser sol-gel processing, Surface \& Coatings Technology 201 (2007) 58095814 